\title{
SCHAEFFER, Ursula, Schriftlichkeit im frühen \\ Mittelalter
}

Joseph Morsel

\section{OpenEdition}

Journals

Édition électronique

URL : http://journals.openedition.org/ifha/1974

DOI : $10.4000 /$ ifha. 1974

ISSN : 2198-8943

Éditeur

IFRA - Institut franco-allemand (sciences historiques et sociales)

Référence électronique

Joseph Morsel, «SCHAEFFER, Ursula, Schriftlichkeit im frühen Mittelalter », Revue de l'IFHA [En ligne], Date de recension, mis en ligne le 01 janvier 1994, consulté le 22 septembre 2020. URL : http:// journals.openedition.org/ifha/1974; DOI : https://doi.org/10.4000/ifha.1974

Ce document a été généré automatiquement le 22 septembre 2020

(C)IFHA 


\title{
SCHAEFFER, Ursula, Schriftlichkeit im frühen Mittelalter
}

\author{
Joseph Morsel
}

La "scripturalité« (Schriftlichkeit, literacy) constitue l'un des maitres-mots actuels de la médiévistique (sinon des sciences humaines en général) d'Outre-Rhin. En témoignent la multiplication des ouvrages qui lui sont consacrés, mais aussi l'existence de groupes de travail comme le Sonderforschungsbereich (SFB) 231 »Agents, champs et formes de scripturalité pragmatique au Moyen Age« (Münster) ou encore le SFB 321 »Transitions et tensions entre oralité et scripturalité« (Fribourg). Ce déplacement de l'intérêt du texte à l'écriture, c'est-à-dire à sa condition de possibilité, est-il l'expression allemande $\mathrm{du}$ »tournant linguistique« issu de la réception aux Etats-Unis des travaux de Derrida? Ou s'agit-il d'un nouvel avatar du relativisme historique allant de pair avec la revigoration actuelle de l'historicisme? Quoi qu'il en soit, la forme majoritairement collective des ouvrages et des projets de recherches à ce sujet montre assez bien qu'il s'agit d'un thème en plein débat et qui fait l'objet de multiples approches. Cette dimension »inachevée« explique sans doute l'extrême variabilité sémantique et lexicale que l'on peut observer. Schriftlichkeit, Verschriftung, Verschriftlichung, Schriftgebrauch: autant d'expressions qui évoquent un recours à l'écriture sans pour autant être synonymes - mais dont les utilisations restent largement équivoques. La troisième partie de l'ouvrage dirigé par U.S. est symptomatique de cette situation, où l'examen des modes de mise par écrit (indépendamment du type de texte) voisine avec des tentatives de précision des rapports oralité/scripturalité. "Scripturalité» (Schriftlichkeit) devrait être réservé au choix du médium écrit par opposition (et donc par rapport) à la communication orale (oralité, Mündlichkeit, orality). Voici quelques ouvrages récents qui tournent autour du problème de la communication, du passage du mot au texte, et du texte au livre.

Le mot est historiquement le premier point de contact entre oralité et scripturalité, entre profération et notation. L'Occident médiéval a vécu sur cette mise en phase et cette transmutabilité du Verbe et de l'Ecriture (figure de l'Incarnation), Verbe noté sous la dictée divine et Ecriture verbalisée par le sermon. Contrairement à ce que laisse penser le titre, l'ouvrage de W.P.K. remonte (consécutivement) aux derniers feux de la 
théorie médiévale du mot/Verbe (Nicolas de Cues, Raymond Lull), avant de passer aux théoriciens de la Renaissance (Reuchlin, Paracelse, Ficin, Pic de la Mirandole, etc.) et à leurs diverses conceptions du mot, mais aussi du signe et du livre (la métaphore du livre est au cœur de la théorie de la perception du sens des choses). Sont enfin abordées les théories linguistiques des XVIe-XVIIe s. qui dépassent le simple niveau du mot (Böhme, Mercurius van Helmont, Bibliander, Gesner, Postel, Hutter, Comenius).

L'histoire de l'écriture reste à écrire, si l'on entend par là autre chose que la description et la datation des différents "systèmes scripturaux". Schrift représente une notable contribution à cette histoire, examinée à travers vingt-cinq contributions qui vont de la Mésopotamie ancienne à l'ordinateur sans frontières d'aujourd'hui, de l'Extrême-Orient à l'Occident, de saint Augustin à Derrida ... Ecriture et pouvoir, écriture et culture, écriture et littérature, écriture et texte (ou »hors-texte«), écriture et visualité: tels sont les principaux thèmes abordés par cet ouvrage à connaître.

Ce sont surtout, en Allemagne comme dans les pays anglo-saxons (cf. McKitterick), les historiens du haut Moyen Age qui se sont préoccupés de scripturalité. Le volume dirigé par U.S. prolonge cet intérêt, auquel on doit aussi rattacher le catalogue de l'exposition sur le scriptorium de Seeon. Le choix du thème de cette dernière (réalisée à l'occasion du millième anniversaire de la fondation du monastère bavarois) a été motivé par le fait que les manuscrits médiévaux ne sont la plupart du temps exposés qu'en raison de leurs enluminures ou de leur texte, mais rarement de leur écriture, comme si les scriptoria n'étaient que des ateliers de peinture ou d'enregistrement de textes. L'exposition entendait donc mettre en valeur cette dimension négligée (le scriptorium comme lieu d'écriture) et avec elle la culture scripturale qui animait les monastères bénédictins du XIe s. - laquelle est évoquée en première partie et fait aussi précisément l'objet de la première partie du volume dirigé par U.S. (quatre contributions, portant sur les rapports entre Bénédictins et culture écrite, sur la lectio divina et sur les rapports entre culture/langue savante et culture/langue populaire en Angleterre). Après un rappel historique des origines du monastère de Seeon, l'exposition (et le catalogue) aborde les aspects proprement techniques de la réalisation d'un codex dans un scriptorium: matériaux employés pour le support, l'encre, la peinture et la reliure, les procédés et connaissances techniques - mais aussi les méthodes actuelles de restauration des manuscrits. Une quinzaine de manuscrits réalisés à Seeon au XIe s. sont enfin présentés, dont les plus belles illustrations (!) ornent le catalogue. Un ouvrage fortement orienté vers la technique, laquelle doit cependant être prise en compte pour préciser la valeur sociale de l'écrit et de l'écriture à cette époque: il existe de toute évidence un rapport d'interdépendance entre l'importance accordée aux activités des scriptoria (dans leur contenu comme dans leur forme technique) et la valeur sociale qui peut s'attacher au document écrit du simple fait qu'il est écrit - et que la croyance en une magie de l'écriture pourrait d'une certaine manière permettre de mesurer: la deuxième partie de l'ouvrage dirigé par U.S. y est consacrée (trois contributions, concernant notamment l'Angleterre), tout comme un passage de l'ouvrage de W.P.K.

Et c'est d'une certaine manière le thème de l'ouvrage dirigé par P.G. Car bien que le thème annoncé soit celui de la force magique que recèle le livre, c'est bien souvent en fait de la force magique de l'écriture qu'il est fait question. Il est vrai que le fait d'être un texte écrit est en définitive le seul point commun aux objets ici regroupés sous la catégorie »livre« (incluant les rouleaux de papyrus et les tables de pierre et tablettes d'argile anciens, les runes et les codices médiévaux et modernes). Il est clair toutefois 
que dans les "religions du Livre (bibliôn)«, le livre lui-même a pu devenir un objet de culte en tant que tel et être doté de forces que l'on regroupe sous l'étiquette de »magie« (contributions de J. VEZIN, A. BOUREAU et A. ANGENENDT). L'avènement d'une conception rationalisante de l'écriture (et de l'imprimerie) a déplacé les enjeux du livre, objet magique de culture et de pouvoir à l'époque moderne et dans les sociétés coloniales.

La cour constitue une sorte de lieu intermédiaire entre ces deux mondes de l'écriture et du livre, comme le montre le cas de la cour de l'Electeur palatin à Heidelberg au XVe s., dont l'usage de l'écrit et du livre est étudié en sept études assemblées par J.-D.M. Là, la possession de livres relève encore de l'univers antérieur et d'une conception particulière de l'écriture (moyen d'échapper au temps), mais la production de ceux-ci répond de plus en plus spécifiquement à des impératifs de transmission du savoir (œuvre d'Albert le Grand, ouvrages militaires et martiaux, compendiums pratiques, etc.). Le savoir devient à la cour un aspect essentiel de l'alchimie sociale: le courtisan est un homme de savoir, ce qui détermine une nouvelle fonction de l'écriture et du livre, alors qu'il était auparavant un homme d'action. L'épée est remplacée moins par la plume que par la lecture.

Joseph MORSEL 